\title{
This Must Surely be the Way to Happiness!: Divergent "bite-size wisdoms" About Happiness in Inspirational Internet Memes
}

\author{
By \\ Jennifer de Paola and Eemeli Hakoköngäs
}

\begin{abstract}
The present study explores the contents and functions of inspirational memes addressing happiness in two cultural contexts, Finnish and Italian. Inspirational memes are understood as a mode of present-day folk wisdom conveying advice that can be easily memorized, shared and applied in everyday life. The material consists of 709 memes collected from Instagram and Facebook in 2019 (N=353 in Finnish; N=356 in Italian). The theoretical background of the study draws from social representation theory. The analysis shows that the contents and functions of inspirational memes addressing happiness are similar in the Finnish and Italian contexts. Five common themes were identified: "the self", "the others", "the life goal", "the here \& now", and "the pointless search". Furthermore, the social representation of happiness within the material is organized around a fundamental dichotomy: on the one hand, happiness can be built, and detailed advice is dispensed on how this can be achieved; on the other hand, building happiness is represented as an unattainable goal, and supporting this view is the idea that happiness is found in the moment. The dichotomy implies a social representation that emphasizes internal factors of the individual and plays down the role of external circumstances in achieving happiness.
\end{abstract}

Keywords: Happiness, social media, social representation, inspirational memes, everyday thinking.

De Paola, Jennifer \& Eemeli Hakoköngäs: "This Must Surely be the Way to Happiness!: Divergent 'bite-size wisdoms' About Happiness in Inspirational Internet Memes", Culture Unbound, Volume 12, issue 3, 2020: 590-614. Published by Linköping University Electronic Press: http://www.cultureunbound.ep.liu.se 


\section{Introduction}

"The wisdom of the wise and the experience of the ages is preserved into perpetuity by a nation's proverbs, fables, folk sayings and quotations."

- William Feather

When his friends invited him to see a monk giving a motivational talk, 18-year-old business student Jay Shetty accepted half-heartedly: "I'm only going if we are going to a bar afterwards." However, profoundly moved by the monk's inspirational words, Jay surprised himself and his friends by deciding to trade his business suit for a saffron robe, embarking on a journey across India to find the true meaning of life. Three years later, on a quest to make "wisdom go viral", he started sharing on social media what he had learnt as a monk in the form of inspirational quotes and short videos, which he describes as "tips and tricks for a fulfilling, happy and successful life" (YouTube 2013).

At the time of writing, Shetty's "bits of wisdom" have raked an impressive 26 million followers on his Facebook page (Facebook 2020). The posts created and shared by Jay Shetty are an example, among many others, of the exponential growth of such "bite-size" content, centred on positive thinking, which is sweeping through social media. Rieger and Klimmit (2019) employ the term "eudaimonic entertainment" to define this type of motivational communication enacted on social media. The concept is based on the division between hedonic (pleasure-seeking) and eudaimonic (meaning-seeking) modes of entertainment (e.g. Oliver and Bartsch 2010). Rieger and Klimmit (2019) extend the concept to describe social media practices. Unlike hedonic entertainment, which intends to elicit a pleasurable affective state, the eudaimonic mode extends beyond mere enjoyment, adding meaningfulness and inspiration as central intents of the content.

While the hedonic entertainment in social media has received much attention, for example, through studies exploring the propagation of internet memes combining text and image to produce viral humour (e.g. Oliveira et al. 2016), its eudaimonic counterpart has only recently become a topic of interest. And yet, YouTube channels, Instagram profiles and Facebook pages overflow with inspirational discourse centred on happiness, personal growth and positive thinking in general. The present study seeks to participate in the scholarly discussion on social media's eudaimonic entertainment, exploring the content and function of inspirational memes centred on happiness, as this topic has recently been shown to be one among the most prevalent themes found in inspirational memes in social media (Rieger \& Klimmit 2019). We define inspirational memes 
as quotes, aphorisms, proverbs or other types of motivational text that social media users have digitally superimposed on an image.

Memes in general have become a topic of interest among scholars from different disciplines in recent years (e.g. Zannettou et al. 2018). Inspirational memes, on the other hand, with the exception of a limited number of studies (e.g. Rieger \& Klimmit 2019), have not received as much attention in scholarly literature. While they share many similarities with hedonic memes, such as being created as a composition of text and image and their highly "shareable" nature, there are also some important differences. Hedonic memes are in fact defined by the widespread use of humorous text, which is usually typed in a plain white font and superimposed on what are often virally shared images, in order to accomplish various rhetorical and communicative functions through humour (Hakoköngäs et al. 2020). Inspirational memes instead combine different kinds of fonts, colours and images and/or backgrounds to create a graphically and aesthetically appealing quote. The functions of inspirational memes in the context of new media specifically has not been studied, but Uski and Lampinen (2016) suggest that in general, the actions in social media follow social norms-what is found appropriate to share in certain context. On the other hand, they serve in the construction of a social media user's authenticity.

In the present study, we decided to focus on inspirational memes shared on the social media sites Facebook and Instagram, due to the inherent affordances and modalities of communication characterizing these platforms. Instagram's emphasis on image sharing and Facebook's vast range of options for sharing both textual and visual material (Shane-Simpson et al. 2018) provide a fertile ground for creating, sharing and modifying memes.

\section{What Inspires Inspirational Memes?}

While inspirational memes started circulating with the advent of social media, cultural artefacts offering "accessible knowledge" on a variety of issues have circulated in different cultural contexts for a long time, for example, in the form of maxims and short sayings, and later on in the form of self-help books (e.g. Lauhakangas 2007; Cherry 2008).

Defined as one of Western culture's preferred sources of enlightenment on how to achieve a better life and improve well-being (Collingsworth 2014), self-help books could be considered long-established forerunners of inspirational memes. In fact, similarly to inspirational memes' intent to inspire and motivate social media users (Rieger \& Klimmit 2019), the self-help book industry motivates readers to take action in their life, conveying the idea that people are entitled to well-being, flourishing and self-development (Collingsworth 2014; Cherry 2008). 
According to folklore scholar Sandra Dolby (2005), self-help books often employ proverbs (or proverb-like language) to deliver the practical advice the author wants to convey; appearing in the form of a short saying, such advice can be easily memorized, shared and applied in everyday life. Thus, the teachings conveyed through the inspirational talks found in self-help books and nowadays condensed in the form of inspirational memes largely draw from "repertoires of folk wisdom". This corpus of knowledge includes short sayings embedding common-sense truths in the form of proverbs, metaphors, allegorical images and aphorisms, and circulated in everyday, culturally situated discourses in all cultures (Fletcher 1984; White 1987; Furnham 1988).

Repertoires of folk wisdom work in a multifunctional manner to explain different situations and to give advice and warnings concerning different ways of thinking or behaviour (Lauhakangas 2007). At the same time, scholars have underlined the beguiling nature of the call for action embedded in commonsensical truth. More specifically, Furnham (1988) pointed out how famous sayings do not offer straightforward directions on how to approach a salient phenomenon. For instance, the popular phrases "out of sight, out of mind" versus "absence makes the heart grow fonder" are an example of contradicting proverbs; the former claims that something (or someone) is easily forgotten when they are absent, while the latter suggests that it is this unavailability which makes us more captivated by the absent object or person. As illustrated with this example, commonsensical truths do not propose unanimous and concise guidance, but rather take ambiguous stances, which can be moulded to the situation at hand (Furnham 1988). This conundrum can also be seen in different advice found in self-help books, which offer different truths and divergent strategies for attaining a desired outcome (Collingsworth 2014).

In spite of such dilemmas, Dolby (2005) criticizes scholarly literature that takes a dismissive stance towards self-help books and rules them out as "misleading quackery", instead proposing that such texts constitute a prolific source of material for tapping into the cultural frame that individuals draw upon when assimilating and maintaining the shared values that define a society. More specifically, the shared narrative behind the corpus of self-help books relies on the underlying assumption that something is missing-happiness, success, one's purpose in life or wealth - and that the suggested course of action can "liquidate" these absences (Dolby 2005). Similarly, in their analysis of the contemporary popular discourse around the "good life" in Sweden, Enstedt and Hermansson (2018) reveal that the message conveyed by Scandinavian self-help books is that by taking control of our lives, and by changing our attitudes and actions according to the instructions given, we become better and happier people in spite of external circumstances. 
The starting point of our study builds on the observed preoccupation of our society to constantly improve ourselves and pursue happiness, which Wright (2014: 795) refers to as "the contemporary cult of happiness". Comparable to "snippets" found in self-help books, we consider inspirational memes as digital vehicles of everyday communication drawing from and constructing cultural conceptions of happiness.

\section{Happiness as a Social Representation}

As noted by Wright (2014), the vast majority of scholarly happiness research relies on two prevalent empirical methodologies: experience sampling, in which the researcher invites participants to report their moods and feelings, and life satisfaction scales, where participants can express their level of agreement or disagreement with life satisfaction-related questions on a Likert scale. While the former methodology presents problems related to the validity of self-reporting due to the fleeting nature of emotions, the use of scales imposes predetermined categories for measuring the levels and causes of happiness, sidestepping commonsensical understandings and lay theories of the concept. Studies adopting a different epistemological standpoint have shown how repertoires of folk wisdom can offer insight into the cultural understandings of intangible entities, such as happiness (Kövecses 2008). For example, in his research on conventionalized linguistic expressions relating to happiness, Kövecses (2005) shows that the four metaphors up, light, fluid and in a container are common conceptualizations of happiness in various unrelated languages and cultures, such as Chinese, Hungarian and English.

In the present study, we consider the conceptualizations and meanings of happiness to be shaped and negotiated through social practices (Sointu 2005; Simpson \& Murr 2014). We propose that folk wisdom, including inspirational memes, related to happiness can be approached as social representations of happiness, that is, socially shared and constructed ideas and practices. Social representations refer to values, ideas and practices shared by a certain group, which facilitate social communication and help people orientate to the social world (Moscovici 1973: xiii). Social representations can be described as everyday knowledge that is constructed in communication between members of a group (for example, in social media). According to this approach, everyday knowledge is formed through two main processes, anchoring and objectification (Moscovici 2008). Anchoring refers to the process by means of which something unfamiliar or an object that is difficult to understand is made familiar and meaningful through connection to something already known. Objectification involves the process by which something abstract-in the context of this study, the idea of happiness-is 
made tangible, for example, through a metaphor, a person or an image (Wagner et al. 1999).

Marková (2003) has emphasized that the construction and structuring of social representations are inseparable parts of human thinking in the social world. Underneath the visible aspect of social representations lies the unnoticed general structure called themata. According to Moscovici and Vignaux (1994), social conceptions are often, if not always, constructed around oppositional categories, such as clean/unclean. These oppositional categories give the representation its inner meaning and provide material for constructing new emerging representations.

According to Moscovici (2008), everyday knowledge is flexible and dynamic by nature, which means that humans can functionally draw from different conceptions to explain changing social situations. Cognitive polyphasia refers to the idea that human thinking is characterized by contradictions and a selective use of information (Jovchelovitch \& Priego-Hernandez 2015). The use of folk wisdom is a classic example of the dynamics of polyphasic thinking; popular sayings are usually widely known, even across cultures. Proverbs, for example, are used as guidelines for counsel in different life situations, and people use proverbs selectively to reinforce a desirable view in each case (Lauhakangas 2007). On the other hand, previous studies (e.g. King 1989) have highlighted the adaptability of folk wisdom, showing that at some points in history, for various concomitant reasons, popular sayings can be modified, sometimes with the result of brand new expressions being coined. King (1989) has pointed out how chengyu (a traditional Chinese idiomatic expression consisting of four characters), meaning "press forward in the way of difficulties", is a relatively modern proverb constructed on the linguistic structure of an older one: "withdraw after learning of the difficulties". Thus, similar to how social representations reflect a group's shared values and psychological situation in a certain moment (Liu 2004), folk wisdom also reflects topical issues in the society in which they are employed.

The main aim of our study is to gain a more nuanced understanding of current folk wisdom related to happiness circulating on social media. In pursuit of this aim, we draw from social representation theory (SRT) to explore the content and function of inspirational memes centred on happiness in two cultural contexts, Finnish and Italian. More specifically, we posed the following research questions:

1) What are the contents of inspirational memes addressing happiness in Finnish and Italian contexts?

2) What kinds of functions are served by the different contents in inspirational memes? 


\section{Method}

\section{Material and cultural contexts}

Our study is based on memes focusing on happiness in two cultural contexts: Finnish and Italian. Our reason for choosing Finnish inspirational memes on happiness is twofold. First, the World Happiness Report (WHR) has granted Finland the title of the happiest country in the world for three consecutive years since 2018 (Helliwell et al. 2020) making "happiness" a socially salient topic among Finns. Secondly, being part of the Finno-Ugric family, Finnish stands apart from most other European languages, offering the opportunity to explore how quotes and concepts of happiness have merged in a specific language area. While Italy and Finland are both European countries and part of Western culture, they differ in terms of their ranking in the WHR, which places Italy in 30th place (in 2020) (Helliwell et al. 2020). As a Mediterranean country, Italy is also geographically distinct from Finland, a Nordic country lying in the boreal zone. Finally, in terms of language characteristics, the comparison is justified as Finnish and Italian are exclusively spoken, respectively, in Finland (with the exception of a small language minority in Sweden) and Italy (with the exception of small language minorities in San Marino, Switzerland and Vatican City), allowing reasonably even grounds for comparison. The first and second authors of the study are native speakers of Italian and Finnish, respectively. In addition, the first author is also fluent in Finnish.

When we looked into how memes focusing on happiness in Finnish and Italian could be searched for on social media, we identified a list of popular hashtags which yielded significant results on Instagram. The Finnish list includes \#onnellinen (happy) ( $\mathrm{N}=159$ 638); \#onnellisuus (happiness) ( $\mathrm{N}=35$ 967) and \#sitaatit (quotes) ( $\mathrm{N}=3$ 182). Similarly, the hashtag lists for the Italian data included \#felice (happy) ( $\mathrm{N}=1100000)$, \#felicità (happiness) $(\mathrm{N}=892000)$ and \#aforismi (aphorisms) ( $\mathrm{N}=1700$ 000). Compared to the Finnish and Italian equivalent of 'happiness' and 'happy', other hashtags connected to the concept of happiness, such as the equivalents of 'joy', 'joyous' or 'well-being', were less popular. We propose this reflects the terms 'happy' or 'happiness' being more prominent, compared to other synonyms in everyday spoken Finnish and Italian. We collected a total of 709 images $(\mathrm{N}=353$ in Finnish and $\mathrm{N}=356$ in Italian) from Instagram and Facebook, using a free social media scraping application in the browser. The research material was collected between May and August 2019.

In the present study, we used the following inclusion criteria to guide our data collection: (1) the post had to include a hashtag concerning happiness; (2) the image had to respect the technical description of a meme, consisting of a combination of textual and visual elements (including plain and/or colourful 
backgrounds); (3) the quote itself had to contain the Finnish or Italian words 'happiness' or 'happy'; and (4) the posts from which the images were retrieved had to be publicly available.

\section{Data-driven and Theory-driven Content Analysis}

To answer the research objectives, the collected inspirational memes were analysed by means of two-step analysis (see Hakoköngäs et al. 2020 for a similar approach). First, to provide a systematic and comprehensive description of the contents of memes addressing happiness in Finland and Italy, the material was analysed by using qualitative data-driven content analysis (Research question 1) (Bauer 2000). We adopted a bottom-up analytical approach, beginning with familiarization with the material. Both researchers read the material several times, adding labels to the memes to describe their characteristic content (e.g. "Happiness as one's own responsibility" or "The other people bring happiness") and construct an initial set of themes. After the first round of analysis, we compared our interpretations, discussed the labels we had created, merged small themes together, and agreed on the final themes. The material was multimodal by nature, containing both textual and visual elements (e.g. images, colours). Even though these different elements together build the overall meaning of the meme, we realized during the content analysis that the role of visual elements was often decorative and the same images could be used to accompany different themes. Thus, for practical reasons we decided to analyse the contents of texts and images separately.

After data-driven content analysis, the labelled themes were examined through theory-driven analysis, in which social representation theory (Moscovici 2008) formed the guiding theoretical framework. In this phase of the analysis, we analysed how happiness was objectified (i.e. made tangible) and how happiness was anchored (i.e. given meaning) within each identified theme. The identification of these processes resembles semiotic reading in which objectifications are identified by observing the literal meaning (denotation) of the material, while the anchoring is based on associations (connotations) (Veltri 2015). In practice, for example the quote "Do not ever put the key to your happiness in someone else's pocket" was in the data-driven content analysis labelled below the theme "Self". In the theory-driven phase, happiness was interpreted to be objectified as a lock that can be open or closed. This image was anchored to the idea of keeping the key to the lock of one's own hands (i.e. emphasizing one's own agency in acquiring happiness). Finally, theory-driven analysis made it possible to interpret the themata of social representations of happiness (i.e. organizing dichotomies) (Moscovici \& Vignaux 1994) and elaborate the functions served by the different contents (Research question 2). 


\section{Results: "Do it! Build your happiness" vs. "Stop! You cannot build happiness"}

We used qualitative data-driven content analysis in combination with methodological tools provided by social representation theory to examine the textual and visual contents appearing in inspirational memes addressing happiness. As there was great variety in the memes in terms of the relationship between the textual and visual contents, we have chosen to report our analysis of the visual elements separately.

The contents of the inspirational memes revolved around common themes in both cultural contexts. As a result of the two-step analysis, we detected two divergent modes of conceptualizing happiness. On the one hand, according to inspirational memes, happiness can be built and detailed advice dispensed on how this can be achieved. This aspect comprised the themes: The Self, The Others and The Life Goal. On the other hand, building happiness is represented as an unattainable goal; supporting this opposite view of happiness are the ideas that happiness is found in the moment (and therefore already present) or that the very act of looking for happiness might paradoxically bring unhappiness. These represent the themes: The Here \& Now and The Pointless Search. We interpreted the resulting dichotomous predicament "Do it! Build your happiness" versus "Stop! You cannot build happiness" as constituting the main thema (antinomy) in the social representation of happiness constructed and shared in the memes. The overall content (themes, objectifications and anchoring) and structure (themata) of the social representations are summarized in Table 1.

\begin{tabular}{|c|c|c|c|}
\hline Themes & Objectifications & Anchorings & Themata \\
\hline THE SELF & $\begin{array}{l}\text { Mindset, } \\
\text { Beauty }\end{array}$ & Agency & \\
\hline THE OTHERS & $\begin{array}{l}\text { Social relationships } \\
\text { [Romance (Italy)] }\end{array}$ & $\begin{array}{l}\text { Belonging, } \\
\text { Helping } \\
\text { [Goodness (Italy)] }\end{array}$ & $\begin{array}{l}\text { DOIT! } \\
\text { BUILD YOUR }\end{array}$ \\
\hline THE LIFE GOAL & $\begin{array}{l}\text { Ready recipes } \\
\text { Rights/duties } \\
\text { Questions }\end{array}$ & Becoming happier & HAPPINESS \\
\hline THE HERE \& NOW & $\begin{array}{l}\text { Mindfulness, } \\
\text { [Forgetfulness (Italy)], } \\
\text { Small things, Gratitude }\end{array}$ & Awareness & \\
\hline $\begin{array}{l}\text { THE PONTLESS } \\
\text { SEARCH }\end{array}$ & $\begin{array}{l}\text { Chase, } \\
\text { Journey }\end{array}$ & Acceptance & $\begin{array}{l}\text { STOP! } \\
\text { YOU CANNOT } \\
\text { BUILD HAPPINESS }\end{array}$ \\
\hline
\end{tabular}


Next, we will describe the characteristics of each theme in more detail, along with interpretations of the meaning-making process conveyed through objectification and anchoring. Finally, we will give a presentation of the findings related to the visual contents and functions in the memes.

\section{Textual Analysis: Contents, Anchorings and Objectifications}

\section{The Self}

In this theme, the textual components of the memes objectify the self as the only possible source of happiness in both cultural contexts. Taking control of our own thoughts, keeping a positive attitude and taking care of ourselves first (in spite of others and what they expect from us) is what it takes to live a happy life. In both Finland and Italy, the self is anchored to the concepts of self-enhancement and agency. The path to happiness rests in our ability to be in charge of it ourselves. Happiness is to be found within, and we are warned against relying on others to make us happy, as demonstrated in the following quotes: "Do not ever put the key to your happiness in someone else's pocket" (Finnish), ${ }^{1}$ and "You will find happiness when you stop asking others to make you happy" (Italian). ${ }^{2}$

More specifically, "others" are represented as being unhelpful or even a hindrance in our quest to find happiness. If others cannot be included as a possible source for our happiness, they are also to be excluded from being the receivers of actions and decisions aimed at increasing happiness, or else our own happiness will be at risk. In that sense, the self becomes at the same time the source and the target of our happiness. We are, for example, explicitly encouraged to think first of ourselves and what makes us personally happy. This predicament is extended to justify choosing happiness over other virtues, including righteousness, generosity or, more abstractly, perfection: "If you are trapped between your feelings and others' opinions, always choose the solution that will make you happy. Unless you want everyone else to be happy other than yourself" (Finnish). ${ }^{3}$ This is expressed more blatantly in the Italian context: "My plan is to be happy, not perfect" (Italian). ${ }^{4}$

The message of the theme is clear: happiness depends entirely on our choices, and it is objectified in the form of our positive thoughts, internal attitude or mindset. At the same time, being happy is also embodied in our physical appearance: "Happiness suits you" (Finnish), and "You can spend hours making yourself beautiful in front of the mirror, but you'll never be as beautiful as when you are happy" (Italian). ${ }^{6}$ 


\section{The Others}

In this theme, the path to happiness is represented as the presence of other people in our lives. In both cultural contexts, the theme "others" is objectified through important others: friends and family (especially motherhood). However, Italian memes are decidedly and more concretely objectified in relation to love and romance. The anchoring of "others" in connection to happiness appears to be twofold. First, in both Finnish and Italian, relationships with meaningful others are anchored to the need to belong: "Happiness is spending time with the people who turn an ordinary day into a wonderful day" (Finnish), ${ }^{7}$ and "Let us be grateful to people who make us happy-they are the charming gardeners who make our souls blossom" (Italian). ${ }^{8}$

Secondly, the importance of others is anchored to the concepts of helping and altruism. Helping others is portrayed as a more enlightened way to reach happiness, as opposed to focusing on ourselves: "...if you want to be happy for your entire life, help others" (Finnish), ${ }^{9}$ and "When you forget wanting to fill your own cup of happiness and you start filling others' cups, you will find that, surprisingly, your own cup will always be full" (Italian). ${ }^{10}$

The anchoring to goodness was something unique to the Italian data: happy people are portrayed as having a direct positive influence on others, because being happy makes us good people, as opposed to unhappy people being envious and judgmental: "Happy people don't waste their time being mean to others. Mean people are unhappy, frustrated, mediocre and envious" (Italian). ${ }^{11}$

\section{The Life Goal}

The theme presenting happiness as a "life goal" includes different views on happiness as something to achieve, along with detailed advice on how to become happy. Advice is often objectified through "ready recipes", "steps" or "rules", which will result in happiness for the reader who follows them. The elements making up these scripts are various and often include different aspects of life, mirroring many of the aspects found in more detail in the entire data set. For example, one finds "The mathematics of life: life+ laughter $\mathrm{x}$ love-hate = happiness" (Finnish), ${ }^{12}$ and "The 5 rules to live happy: 1) Do not hate. 2) Do not worry. 3) Donate more. 4) Have less expectations. 5) Live simply" (Italian). ${ }^{13}$

Along with dispensing advice on how to achieve happiness, in both contexts happiness was objectified as either a right or a duty, expressed through the idea that we all want (and deserve) happiness: "The meaning of life is to be crazy happy" (Finnish) ${ }^{14}$ and "You are born to be happy, don't get distracted!" (Italian). ${ }^{15}$

The idea of happiness as a life goal is anchored to the concept of happiness as something which is not only achieved but also constantly improved, making 
happiness the ultimate meaning of our existence. Finally, beside arguments in support of and advice on how to become happier, in this category in both contexts the quotes engage in conversation about how happiness can be achieved and improved. This is seen in direct questions to the reader: "What are the things that bring you happiness?" (Finnish) ${ }^{16}$ and "Where do you find happiness?" (Italian). ${ }^{17}$

\section{The Here \& Now}

In this theme, happiness is represented as a fleeting feeling, which we can savour by suspending the frenzy of our lives and living in the moment. In both contexts, this message was presented in connection with the idea of mindfulness and mindful living: "Happiness is in this exact moment when I have time to stop by its side" (Finnish) ${ }^{18}$ and "When you are happy, notice it" (Italian). ${ }^{19}$ However, the Italian data also present the possibility of finding happiness in moments of forgetfulness, as opposed to mindfulness: "Maybe there are tiny moments of happiness. They are the ones in which you forget about bad things. Happiness, my lady, is made up of moments of forgetfulness" (Italian). ${ }^{20}$

The idea of being mindful about the present moment is often objectified in terms of gratitude for the "small things" or, more generally, for the things we have already achieved: "Keep your heart happy and rejoice in small things!" (Finnish) ${ }^{21}$ and "Look around and find in the little things a reason to be happy. Good morning" (Italian). ${ }^{22}$ Although the connection between happiness and gratitude is somewhat close to the concept of the positive mindset presented in the theme The Self, here the focus is on being thankful and having appreciation for one's life circumstances; according to the quotes, these are automatically followed by happiness. In the theme Self, keeping a positive mindset instead represents a more active choice to work towards reaching happiness in spite of external circumstances.

Finally, in both contexts the theme is anchored to awareness: the meaning of happiness is something which needs to be acknowledged, rather than built or found: "One is unhappy because they don't know they are happy" (Finnish), ${ }^{23}$ and "Many people miss out on their chance for happiness, not because they haven't found happiness, but rather because they've never stopped to enjoy it" (Italian) ${ }^{24}$

\section{The Pointless Search}

This theme conveys the concept of the impossibility to actively look for happiness. Both contexts objectify happiness by using the journey metaphor: "Happiness is not a station you can reach. It's a way of travelling" (Finnish), ${ }^{25}$ and "Happiness is not a destination but a way of living" (Italian) ${ }^{26}$ Similarly, but perhaps with more of a negative connotation compared to the journey metaphor, happiness is also 
objectified as a pointless "chase": "Do not search for happiness. If you do, you won't find it, for searching is the antithesis of happiness" (Finnish), ${ }^{27}$ and "Happiness is the absence of the search for happiness" (Italian). ${ }^{28}$ In both contexts, the idea of becoming happy is anchored to the concepts of process and acceptance: the process expresses the dynamic nature of happiness, which can neither be seized at any given moment nor obtained by actively working towards it. Paradoxically, it is through accepting the impossibility of changing our lives in order to be happier that we have a chance at happiness.

\section{Visual Analysis: Images and their Functions}

The initial content analysis indicated that the visual components of the inspirational memes were often not directly related to the meaning of the text but rather acted as a visual embellishment framing the quote, while the main content of the meme was conveyed through the textual component. Nevertheless, considering the nature of image-based social platforms, with users engaging in trying to find ways to give their posts more visibility, we propose that the visual choices accompanying the quotes are worth exploration, and we have chosen to report our analysis of the visual elements presented in the material separately in this section. The main findings are reported in Table 2.

\begin{tabular}{|c|c|c|}
\hline Theme of the visual elements & Location & Description/examples \\
\hline 1. Aesthetics and nature & $\begin{array}{l}\text { Across all data, and } \\
\text { especially in the } \\
\text { Finnish context } \\
\end{array}$ & $\begin{array}{l}\text { Bright and colorful } \\
\text { backgrounds, landscapes, } \\
\text { beaches, flowers, flying items. }\end{array}$ \\
\hline \multirow{5}{*}{ 2. Symbols } & The Self & $\begin{array}{l}\text { Opening/closing symbols: doors, } \\
\text { keys, padlocks, containers; } \\
\text { People smiling, engaging in } \\
\text { power poses, looking up; }\end{array}$ \\
\hline & The Others & $\begin{array}{l}\text { Heart shapes; } \\
\text { Affection between people. }\end{array}$ \\
\hline & The Life Goal & $\begin{array}{l}\text { Formulas, recipes, charts } \\
\text { Bullet points, steps }\end{array}$ \\
\hline & The Here \& Now & $\begin{array}{l}\text { 'Small things': e.g. coffee, close } \\
\text { ups of flowers, people relaxing. }\end{array}$ \\
\hline & The Pointless Search & $\begin{array}{l}\text { Journey metaphors: streets, } \\
\text { forest paths, coastlines. }\end{array}$ \\
\hline 3. Symbolic layout & Across all data & $\begin{array}{l}\text { Visual elements embedded in the } \\
\text { text, for example, different types } \\
\text { of fonts, colors or size used to } \\
\text { enhance part of the text. }\end{array}$ \\
\hline 4. Celebrity/authority endorsement & Across all data & $\begin{array}{l}\text { Local 'celebrities'; } \\
\text { International celebrities and } \\
\text { cartoons (Italian context only); } \\
\text { Philosophers: e.g. Seneca, } \\
\text { Buddah (Italian context only). }\end{array}$ \\
\hline
\end{tabular}


Visual analysis of the memes shows that there were many similarities between the Finnish and Italian contexts in relation to how images were used to objectify happiness in the five aforementioned categories (Table 2). In fact, we even encountered instances of nearly identical memes in both Finnish and Italian, as shown, for example, in Figure 1. This mirrored vignette, showing two individuals discussing a jar with the word 'happiness' written on it, reflects the shared aspect of meme-like images across the internet. In such cases, the message is simplified and made tangible through a comic-style "teaching", which is repeated (almost) identically in other linguistic contexts online.
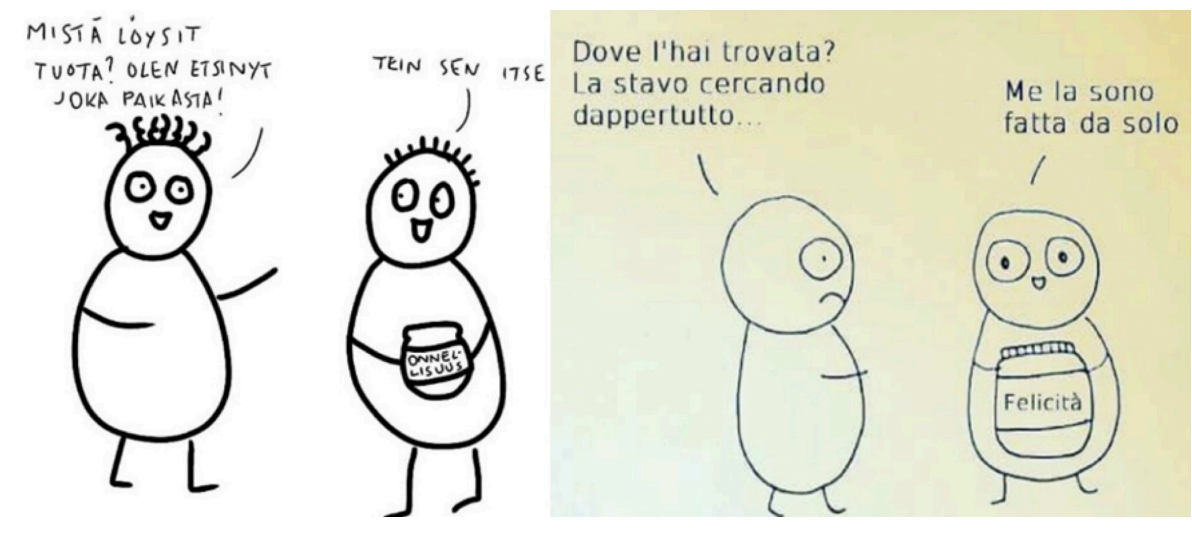

Figure 1. "Where did you find it? I have looked everywhere for it. - I made it myself" (Finnish, left; Italian, right)

Besides showing how memes use images to embellish a quote and/or to corroborate textual objectifications, our analysis shows two additional functions facilitated by the visual components: symbolic layout and expert/celebrity endorsement. Symbolic layout refers to how some memes rely on the visual elements to convey a statement-like message, which directly positions the social media users in the context of negotiating the social meaning of happiness. For example, Figure 2 shows how Eino Leino's famous Finnish poem "The one who is happy hides happiness" is presented in elegant cursive, but with the term "hide" crossed out with a red "X" mark and replaced with a modern, handwritten-looking correction stating "show". This turns the quote into "The one who is happy shows happiness." Similarly, we can see how in the Italian text "My plan is to be happy, not perfect", the word 'perfect', unlike the rest of the text, is typed in a handwritten, "imperfect" style with mismatched capitals and lower case. This simple visual "tweak" is a powerful means to reinforce the meaning of the quote: expressing yourself and your own happiness is more important than abiding by society's standards. 


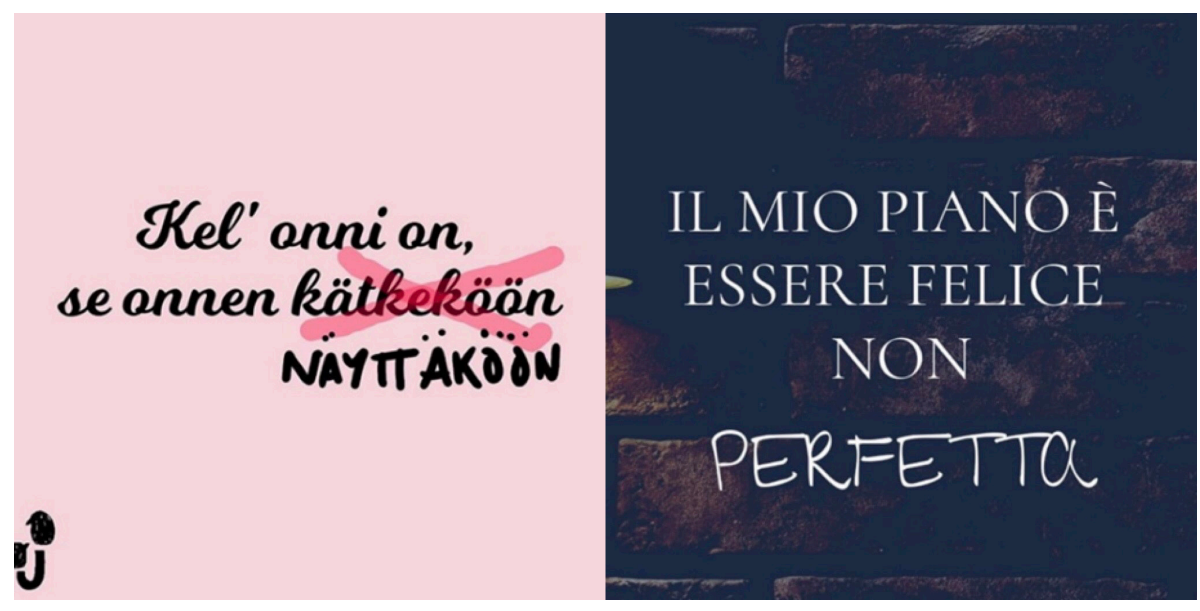

Figure 2. "The one who is happy hides/shows happiness" (Finnish, left), and "I want to be happy, not perfect" (Italian, right)

Finally, the function of celebrity/authority endorsement took various visual forms. The most visible form was represented by portraits of either celebrities or authority figures, who most often (but not necessarily) were also the authors of the quotes. It also appeared to be common in both cultural contexts to adopt the more vague expert endorsement strategy of starting the quote with "psychology says..." or "science says...", as well as simply framing the text between quote marks, conveying the message someone said that before me. In the Italian context, celebrity/authority endorsement appears to be common, compared to the Finnish data.

\section{Discussion}

The primary aim of our study was to explore the content and function of inspirational memes centred on happiness in two cultural contexts, Finnish and Italian. The two-step analysis showed that the contents and meanings conveyed in both textual and visual dimensions in inspirational memes were very similar in the two areas, but it also revealed certain minor differences, especially in the ways happiness was objectified in the Finnish or Italian contexts. The five themes were shared with similar patterns in both Finnish and Italian memes: The Self, The Others, The Life Goal, The Here \& Now and The Pointless Search.

Drawing from methodological tools provided by social representation theory (Moscovici, 2008), we identified a main themata (dichotomy) - "Do it! Build your happiness"/ "Stop! You cannot build your happiness"-organizing the social representation of happiness and characterizing the way happiness should be pursued, according to these inspirational memes. On the one hand, according to the 
predicaments found in The Self, The Others and The Life Goal, the inspirational memes advise that we are able to directly influence our happiness level with our actions. On the other hand, the dominant message in the themes The Here \& Now and The Pointless Search is that happiness is not something to work for, but rather something to be found through gratitude for what we (already) have, including the little things, for happiness can slip through our fingers if we start chasing it. Before discussing the main dichotomy found in the memes, we will discuss each theme separately, interpreting our findings in the light of previous forms of folk knowledge related to happiness found in the literature.

The theme The Self is perhaps the most dominant motif found in inspirational memes, which presents happiness as purely dependent on internal factors. The portrayal of sheer self-mastery in relation to happiness reiterates some of the happiness metaphors that have been noted to occur in various cultural contexts. For example, Happiness is up is a very well-known happiness metaphor, which appears to be in line with how happiness is made tangible in some of these memes. This metaphor has been noted to be widely shared in very different cultural contexts and languages, including English (Kövecses 2005; Lakoff \& Johnson 1980) and Chinese (King 1989), possibly due to the "panhuman expression of lifting one's head up when feeling happy" (King 1989: 136). In the Finnish and Italian memes, images where people are power-posing, reaching out for the sky or simply looking up are commonly used in connection to happiness as both a self-made and self-centred emotion and experience. Happiness as liquid in a container is another very well-known metaphor (Kövecses 2005), which appears to be in line with the memes maintaining that happiness is to be found "within" ourselves. This rather abstract predicament is often made tangible (objectified) through "opening and closing" symbols, expressed through both textual and visual components of the memes. We propose that expressions such as "you hold the key to your happiness" or images of doors, keys and padlocks serve two functions. First, they reinforce the idea that happiness is contained in a "physical" place, located inside of us or within our reach, which can be unlocked by using the right key or, in other terms, by making a conscious decision and performing the right actions. Secondly, the same symbols also represent a "locking" function, which can be used to shield our happiness from the dangerous "other": in the memes we are in fact repeatedly cautioned not to rely on others in any way when it comes to our own happiness.

The theme The Others maintains the exact opposite: happiness is found because someone other than ourselves is present. In this theme, happiness is either anchored to a sense of belonging or to altruism. In the first instance, happiness is derived from the presence of the people we love; their mere presence in our life constitutes the very fabric of happiness. In the latter case, happiness is reached by helping others; according to this view, it is kindness that begets happiness. 
The connection between happiness and altruism can be traced back to the Greek ethical idea of disinterested concern for others as a form of Aristotelian virtue to be practised in pursuit of happiness (Rabbås et al. 2015). In general, the relation between happiness and others is visually represented as affection between people, as well as through various graphical recreations of heart shapes. The amorous heart has persisted since medieval times as an abiding icon of love in many cultural contexts, and therefore its presence in happiness memes centred on relationships is hardly a surprise. The idea of the heart in connection to happiness is also present in various languages; for example, "her heart filled with happiness" is a common expression in the English language (Kövecses 2005), which resonates with the expressions "Sydämeni täyttää ilo" (Finnish) and "il mio cuore si riempie di gioia" (Italian), meaning "my heart fills with joy". Once again, we encounter a metaphor which refers to happiness as something which can be contained, although this time the source of the feeling is placed outside of ourselves. As noted above, the theme The Others has a stronger romantic connotation in the Italian memes than in the Finnish ones. A possible explanation can perhaps be found in the history of literature in the Italian context. Il Dolce Stil Novo, accredited as one of Italy's most influential literary movements, has forged the connection between pledging one's heart to someone special with the aspiration to find earthly bliss.

The theme The Life Goal encompasses a variety of sub-themes pointing in the same direction: the main purpose of our life is to find happiness. The quest for happiness is undertaken through a combination of actions. The way the advice is broken down into steps and lists makes The Life Goal memes highly reminiscent of self-help books. In a very condensed form, these memes base their message on the same assumption underlying the main narrative of self-help books: the lack of something (in this case, happiness) in conjunction with an ad hoc suggestion of the course of action we are to follow to overcome this lack (Dolby 2005). The advice is often objectified through expressions like "The recipe for happiness", "Ten steps to happiness" or "ABCs of happiness", as well as through visual representations of ladders, formulas or other instruction-like images. These suggestions, however, can vary between-as well as within-cultural contexts: in other words, the recommended steps towards happiness, much like the ones we find in self-help books, include different kinds of actions from meme to meme. Nevertheless, the fact that this form of advice has trickled down from self-help books to social media suggests that such "recipes" are appreciated because of the instruction-like layout, inviting the reader or social media user to consult a ready-made list of simple actions that can be implemented in their life.

The advice dispensed in The Here \& Now theme stands in stark contrast to The Life Goal theme's recipe-like recommendations on how to achieve happiness. In the latter, happiness is often set in the near future: the assumption is that we 
should follow a specific set of actions and only then will we achieve what we are lacking (i.e. happiness). In The Here \& Now theme, happiness is not postponed to a future point but found in the present moment through being grateful for what we have achieved so far as well as for the little things that bring joy into our lives.

Similarly to The Here \& Now theme, The Pointless Search theme strongly positions happiness in the present moment. However, if the main rhetorical argument in The Here \& Now focuses on the importance of enjoying the present moment, The Pointless Search extends the outlook to one's entire life. In this scenario, both happiness and life itself are dynamic processes rather than final products. The memes objectify this idea through journey metaphors and images depicting paths, streets and walking. The life as a journey metaphor is deeply rooted in various languages and cultures and expressed through metaphorical sayings, such as finding oneself "at a crossroads" or "at a "roadblock", "lost" or "in a safe place" (Katz \& Taylor 2008: 150). In a similar way, happiness as a journey metaphors, found in both Finnish and Italian contexts, reinforce the idea that the starting point and arrival are not important, as it is the places and experiences in between that truly count. In this view, thinking of happiness as something that we can achieve comes with the danger of putting us in a rut: the more we look for happiness as a static point of arrival, the more we jeopardize our chances of experiencing it. The anchoring of this theme is acceptance: it is when we come to terms with the futility of chasing a non-existent arrival point and accept life for what it is that happiness will find us. This is hardly a new perspective on happiness; indeed, it resonates with the philosophical view on happiness developed and adopted by stoic philosophers in Ancient Rome (e.g. Seneca): desire begets desire, and we should therefore refrain from desiring happiness but rather focus on living a virtuous life.

Overall, while the contents of the five themes are similar in both Finnish and Italian memes, the way in which the content is expressed presents variations reflecting the specific cultural context. For example, while international sayings are present to a certain extent in both Finnish and Italian data, each context employs local celebrities and figures as a medium to communicate the happiness-related advice or wisdom contained in the text. In addition, we noted that the celebrity/ authority endorsement technique, visible in both the textual and visual elements of the memes, is more pervasive in the Italian context. The Finnish context, on the other hand, seems to rely more on nature-related visual elements, ranging from natural landscapes to nature details, such as flowers and leaves. We suggest that the pervasive use of this type of imagery accompanying the quotes is reflective of the meaningful connection between nature and well-being inherent in the Finnish culture (De Paola et al. 2020; Tyrväinen et al. 2019). 
Regarding the similarities between the Finnish and Italian data, in both cultural contexts, two divergent views on how to find happiness emerge from our analysis. On the one hand, happiness is dictated by our choices and actions: favouring a positive mindset, investing in relationships and following happiness "recipes". On the other hand, happiness is to be found through gratitude for what life has to offer at the present moment, and any attempt outside that will jeopardize our chances of finding happiness. The call for action embedded in commonsensical truth is often characterized by such contradictions. For example, we have seen how popular sayings and proverbs often provide contradictory guidelines on the same subjects (Furnham 1988; Lauhakangas 2007) and how self-help books promote divergent strategies for attaining a desired outcome (Collingsworth 2014).

In our study, the inspirational memes analysed confront the social media user with two oppositional calls for action or "directions" related to finding happiness, one saying "do it" and the other one saying "stop". In terms of social representation theory, these divergent "truths" about happiness constitute a thema, that is, a basic antinomy organizing and giving structure to the social representation of happiness in the present context. We propose that the antinomy "do it/stop" constructed in the inspirational memes might reflect contemporary cultural discourses around happiness. The side of the themata addressing happiness as something which can be achieved reiterates self-help books' advice: individuate what is lacking and implement a strategy to liquidate this lack (Dolby 2005). This kind of narrative resonates with the broader cultural discourse around the therapeutic model of dysfunctional behaviour that needs fixing (Conrad 2007). As with self-help books, these types of inspirational memes rely on the social media user to individuate and correct the dysfunctional behaviour by actively doing something. In contrast, the other side of the themata urges the social media users to stop thinking of ways to "fix" things and focus instead on the present moment, thinking of happiness as an abiding process rather than a permanent state. We suggest that the latter call for (no) action is an emergent discourse around well-being and good life, which has gained momentum with the increased popularity of mindfulness and meditation practices in Western culture (Khoury et al. 2017).

To sum up, if inspirational memes propose two divergent strategies for reaching happiness, are we to conclude that there is no consensus on how to understand, represent and pursue happiness in the realm of social media eudaimonic entertainment? We think that may not be the case, and that in fact both ends of the antinomy are part of the same social representation of happiness. In the realm of SRT, thinking in opposition spurs impetus in the discourse around salient topics, thus enabling members of a group or society to take different stances on the same subject depending on the current need (Moloney, Hall and 
Walker 2005). We propose that these two apparently irreconcilable sets of advice on how to find happiness ("Build your happiness" versus "You cannot build happiness") organize in a dialogical structure a social representation of happiness centred on internal factors. In both instances, we are actually called to ignore-or at least downplay-the importance of external circumstances, either by changing our behaviour and mindset (build your happiness) or by accepting that nothing can change, and focusing instead on the present (or the "journey").

The fact that this antinomy is present in both Finnish and Italian data suggests that the cultural contexts considered in this study might be undergoing a similar shift in the conceptualization of happiness as that noted by Enstedt and Hermansson (2018) in the concept of the good life in current Swedish society. While in the past a good life was more associated with religious concepts and, therefore, external circumstances, the increased reverence towards individuality in Western society has gradually shifted the focus towards the self. Our study demonstrates that in the Finnish and Italian contexts, the social renegotiation of the cultural understandings of happiness is an unfolding process. In the results section, we have seen how through inspirational memes, popular quotes can be reshaped to fit more current representations of happiness. For example, the popular Finnish quote "The one who is happy hides happiness" has been visually "tweaked" and turned into "The one who is happy shows happiness." Similarly, in the Italian context the austere tone of the quote "The world belongs to those who wake up early" is smoothed into a more indulgent adaptation: "The world belongs to those who wake up happy." Previous studies (e.g. King 1989) have shown that such changes in popular sayings are often the result of ongoing cultural and societal changes; when a traditional proverb or expression no longer conforms to the corresponding expected behaviour, a new saying which better reflects the current context and social reality is coined. We interpreted the newly created quotes in the inspirational memes mentioned above as reflecting a possible shift in the way happiness is conceptualized in the Finnish and Italian cultural contexts: in both instances, the emphasis is shifted from more pessimistic or authoritative tones towards more positive and self-indulgent connotations of happiness. Part of the reasons behind this change could be attributed to social media platforms representing the main arenas where inspirational memes of various languages are generated and circulated. In that sense, Finnish and Italian cultural understandings of happiness could, in time, be influenced by the cultural aspects inherent in the social media platforms facilitating everyday discourses around happiness. This is already evident in instances of inspirational memes exhibiting identical texts and very similar images in both contexts, as seen in the example "happiness in a jar" (Figure 1). As already noted by Kövecses (2005), it is not uncommon to find nearly identical sayings being shared in different cultural and linguistic 
contexts. The explanation for such similarities appears to be threefold: it can happen by accident, by means of borrowing expressions from another language, or because the expression is elicited by universal motivations and/or experiences (Kövecses 2005). In light of the increased importance of social media, we suggest a fourth possible explanation: it is possible that such similarities are due to the highly sharable nature of memes, which enables them to spread and evolve at a fast pace on different social media platforms and via other means of digital communication, regardless of physical or linguistic barriers. If that is the case, it is crucial to place more attention on the ways in which these new forms of eudaimonic entertainment participate in renegotiations of emic understandings of happiness and its pursuit.

\section{Conclusions}

In the present paper we suggest that eudaimonic entertainment content circulating on social media is too widespread to be overlooked. Yet, as we have seen in the case of self-help books struggling to gain scholarly attention in the past (Dolby 2005), we think there is the risk of inspirational memes being too quickly dismissed by many disciplines as frivolous platitudes. Instead of dismissing these "snippets" of wisdom, we suggest they should be approached as digital vehicles of values and beliefs-social representations-constituting the fabric of different cultural contexts.

With this study, we have strived to demonstrate that inspirational memes do not simply reflect local cultural understandings of happiness in a static way. Our findings show that old sayings about happiness are being adapted to current settings and that new expressions are being coined and shared in different cultural contexts. In addition, we revealed how inspirational memes inform about cultural understandings of the course of actions needed to reach happiness. The present study is not without limitations, however, as it focused solely on the contents of inspirational memes and interpreted their functions. It is likely that social media practices also serve other functions than making sense of socially topical issues; they may, for example, participate in the user's presentation of authenticity, as suggested by Uski and Lampinen (2016). In future studies, the ways in which social media users perceive and use different forms of "eudaimonic entertainment" (Rieger and Klimmit 2019), such as inspirational memes, should be addressed.

In line with our findings is Enstedt and Hermansson's (2018) observation that the increased responsibility placed on individuals to build their happiness can have harmful effects by creating "utopian ideals" of self-mastery, while at the same time societal structures and issues such as inequality are sidestepped. Even worse, the risk could involve perpetuating and circulating a 'brutally normative' ideal of 
happiness, where individuals failing to recognize the transformative power of the mind are vulnerable to marginalization (Wright 2014: 795). Our findings have shown that vis-à-vis the strategy of taking individual action to build happiness, the memes promote a divergent strategy which entails finding gratitude for the status quo and micro-level aspects of life, along with acceptance of the impossibility to reach complete happiness.

While we acknowledge the advantage of both self-empowerment and gratitude practices, we also think it is important to consider how in the current popular discourse on happiness, well-being-related factors, such as socio-economic circumstances, are ignored, as they do not fit the narrative and empowering tones of such bite-size forms of wisdom. In addition, while bite-size knowledge can provide instant boosts of optimism and spur gratitude, their extremely condensed nature may also lead to an overly simplified understanding of our potential to change in the face of societal constrictions (Do it! Build your happiness) and incentivize acceptance towards aspects of society that would perhaps be worth improving (Stop! You cannot build your happiness).

Jennifer De Paola, MPsych(Clin), Sapienza University of Rome, is currently a doctoral candidate employed at the Faculty of Social Sciences, Discipline of Social Psychology, University of Helsinki. De Paola's research focuses on how the concept of happiness is shaped and constructed through images and discourses taking place on various social media platforms and online forums. Email: jennifer. depaola@helsinki.fi

Eemeli Hakoköngäs (Dr. Soc. Sci., University of Helsinki) is a University Lecturer in Social Psychology at the University of Eastern Finland. His research interests include visual culture, collective memory and political psychology. E-mail: eemeli. hakokongas@uef.fi

\section{Notes}

1 "Älä koskaan laita oman onnesi avainta jonkun toisen taskuun."

2 "Troverai la felicità quando smetterai di chiedere agli altri di renderti felice."

3 "Jos olet loukussa tunteidesi ja muiden mielipiteiden välillä, päädy aina ratkaisuun, joka tekee sinut onnelliseksi. Ellet halua kaikkien muiden olevan onnellisia, paitsi sinun."

4 "Il mio piano è essere felice, non perfetta."

5 "Onnellisuus pukee sinua."

6 "Puoi passare ore davanti a uno specchio a farti bella. Ma bella come quando sei felice non lo sarai mai."

7 "Onni on viettää aikaa sellaisten ihmisten kanssa, jotka tekevät aivan tavallisesta päivästä jotain aivan erityistä." 
8 "Dobbiamo essere grati alle persone che ci rendono felici, sono gli affascinanti giardinieri che rendono la nostra anima un fiore."

9 “...Jos haluat olla onnellinen koko loppuelämäsi - auta muita."

10 "Quando smetterai di voler riempire il tuo bicchiere di felicità ed inizierai a riempire quello degli altri, scoprirai, con meraviglia, che il tuo sarà sempre pieno."

11 "Le persone felici non perdono il tempo facendo del male agli altri. Il male è una cosa di gente infelice, frustrata, mediocre e invidiosa."

12 "Elämän matematiikka: elämä + nauru + rakkaus - viha = onnellisuus."

13 "Le 5 regole per vivere felice: 1) Non odiare. 2) Non ti preoccupare. 3) Dona di più.

4) Abbi meno aspettative. 5) Vivi con semplicità."

14 "Elämän tarkoitus on olla ihan sikaonnellinen."

15 "Sei nato per essere felice, non distrarti!"

16 "Mitkä asiat saavat sinut onnelliseksi?"

17 "Ma dove si trova la felicità?"

18 "Onni on tässä hetkessä, kun ehdin pysähtyä sen äärelle."

19 "Quando siete felici, fateci caso."

20 "Forse vi sono momentini minuscoli di felicità, e sono quelli durante i quali si dimenticano le cose brutte. La felicità, signorina mia, è fatta di momenti di dimenticanza."

21 "Pidä sydämesi onnellisena ja iloitse pienistäkin asioista!"

22 "Guardati intorno e cerca nelle cose semplici un motive per essere felice. Buongiorno."

23 "Ihminen on onneton, koska hän ei tiedä olevansa onnellinen."

24 "Molte persone perdono la loro parte di felicità, non perché non l'hanno trovata, ma perché non si sono mai fermata a godersela."

25 "Onnellisuus ei ole asema, jolle saavut vaan tapa matkustaa."

26 "La felicità non dev'essere un punto d'arrivo, ma uno stile di vita."

27 "Älä etsi onnea. Jos etsit, et löydä sitä, sillä etsiminen on onnen vastakohta."

\section{References}

Bauer, Martin W. (2000): “Classical content analysis: A review," Martin W. Bauer \& George Gaskell (eds): Qualitative Researching with Text, Image and Sound, London UK: Sage, 131-151.

Cherry, Scott (2008): "The ontology of a self-help book: A paradox of its own existence," Social Semiotics, 18:3, 337-348.

Collingsworth, Jean (2014): "The Self-Help Book in the Therapeutic Ontosphere: A Postmodern Paradox," Culture Unbound: Journal of Current Cultural Research, $6: 4,755-771$

Conrad, Peter (2007): The medicalization of society: On the transformation of human conditions into treatable disorders, Baltimore USA: JHU Press.

Dolby, Sandra K. (2005): Self-help books: Why Americans keep reading them, Illinois USA: University of Illinois Press. 


\section{Culture Unbound}

Journal of Current Cultural Research

De Paola, Jennifer, Eemeli Hakoköngäs \& Jari Hakanen (2020): “\#Happy: Constructing and Sharing Everyday Understandings of Happiness on Instagram," Human Arena, 1-19.

Enstedt, Daniel, \& Kristina Hermansson, (2018): "Personal Utopia: The "Good Life" in Popular Religion and Literature in Contemporary Sweden," Culture Unbound: Journal of Current Cultural Research, 10:1, 128-150.

Facebook (2020): "Community". https://www.facebook.com/pg/JayShettyIW/ community/?ref=page internal (Accesses 01/03/20)

Fletcher, Garth J. (1984): "Psychology and common sense," American Psychologist, $39: 3,203$

Furnham, Adrian (1988): Lay Theories: Everyday Understanding of Problems in the Social Sciences, Oxford: Pergamon Press.

Hakoköngäs, Eemeli, Otto Halmesvaara, \& Inari Sakki (2020): "Persuasion Through Bitter Humor: Multimodal Discourse Analysis of Rhetoric in Internet Memes of Two Far-Right Groups in Finland," Social Media + Society, 6:2, Online first publication: doi: $10.1177 / 2056305120921575$.

Helliwell, John F. et al. (2020): World Happiness Report 2020, New York: Sustainable Development Solutions Network.

Jovchelovitch, Sandra, \& Jacqueline Priego-Hernandez (2015): "Cognitive polyphasia, knowledge encounters and public spheres," Gordon Sammut et al. (eds): The Cambridge handbook of social representations, Cambridge UK: Cambridge University Press, 163-178.

Katz, Albert N. \& Tamsen E. Taylor (2008): “The journeys of life: Examining a conceptual metaphor with semantic and episodic memory recall," Metaphor and Symbol, 23:3, 148-173.

Khoury, Bassam et al. (2017): "Effectiveness of traditional meditation retreats: A systematic review and meta-analysis," Journal of Psychosomatic Research, 92, $16-25$.

King, Brian (1989): The conceptual structure of emotional experience in Chinese, doctoral dissertation, Ohio State University.

Kövecses, Zoltán (2005): Metaphor in culture: Universality and variation, Cambridge University Press.

Kövecses, Zoltán (2008): “The conceptual structure of happiness," Happiness: Cognition, experience, language, 131-143.

Lauhakangas, Outi (2007): "Use of proverbs and narrative thought," Folklore: Electronic Journal of Folklore, 35, 77-84.

Lakoff, George \& Mark Johnson (1980): "The metaphorical structure of the human conceptual system," Cognitive science, 4:2, 195-208.

Liu, Li (2004): "Sensitising concept, themata and shareness: A dialogical perspective of social representations," Journal for the Theory of Social behaviour, 34:3, 249-264.

Marková, Ivana (2003): Dialogicality and social representations. The dynamics of mind, Cambridge: University of Stirling.

Moloney, Gail, Rob Hall \& Iain Walker (2005): "Social representations and themata: The construction and functioning of social knowledge about donation and transplantation," British journal of social psychology, 44:3, 415-441.

Moscovici, Serge (1973): "Foreword," Claudine Herzlich (ed.): Health and Illness: A Social Analysis, London UK: Academic Press, 9-14.

Moscovici, Serge \& Georges Vignaux (1994): "Le concept de Thêmata" Christian Guimelli (ed.): Structures et transformations des représentations sociales, Neuchâtel: Delachaux et Niestlé, 25-72.

Moscovici, Serge (2008): Psychoanalysis: Its Image and Its Public, Cambridge: Polity. [Originally published 1961] 
Oliveira, Hugo Gonçalo, Diogo Costa \& Alexandre Miguel Pinto (2016): "One does not simply produce funny memes!-explorations on the automatic generation of internet humor," ICCC 2016: Proceedings of the Seventh International Conference on Computational Creativity Paris, France.

Oliver, Mary Beth \& Anne Bartsch (2010) "Appreciation as audience response: Exploring entertainment gratifications beyond hedonism," Human Communication Research, 36:1, 53-81.

Rabbås, Øyvind et al. (2015): The quest for the good life: Ancient philosophers on happiness, Oxford UK: Oxford University Press, 88-112.

Rieger, Diana \& Christoph Klimmit (2019): "The daily dose of digital inspiration: A multi-method exploration of meaningful communication in social media," New Media \& Society, 21:1, 97-118.

Shane-Simpson et al. (2018): "Why do college students prefer Facebook, Twitter, or Instagram? Site affordances, tensions between privacy and self-expression, and implications for social capital," Computers in Human Behavior, 86, 276-288.

Simpson, Graeme \& Ani Murr (2014): "Reconceptualising well-being: Social work, economics and choice," Culture Unbound, 6:4, 891-904.

Sointu, Eeva (2005): "The rise of an ideal: tracing changing discourses of wellbeing," The Sociological Review, 53:2, 255-274.

Tyrväinen, Liisa, et al. (2019): "Health and well-being from forests-experience from Finnish research," Sante Publique, 1:HS, 249-256.

Uski, Suvi \& Airi Lampinen (2016): "Social Norms and Self-Presentation on Social Network Sites: Profile Work in Action," New Media \& Society, 18:3, 447-64.

Veltri, Giuseppe (2015): "Social semiotics and social representations theory," Gordon Sammut et al. (eds): The Cambridge handbook of social representations, Cambridge UK: Cambridge University Press, 234-249.

Wagner, Wolfgang et al. (1999): "Theory and method of social representations," Asian journal of social psychology, 2:1, 95-125.

White, Geoffry M. (1987): "Proverbs and cultural models: An American psychology of problem solving," Dorothy Holland Herring (ed.): Cultural models in language and thought, Cambridge University Press, 151-172.

Wright, Colin (2014): "Happiness studies and wellbeing: A Lacanian critique of contemporary conceptualisations of the cure," Culture Unbound: Journal of Current Cultural Research, 6:4, 791-813.

YouTube (2013): "Jay Shetty". https://www.youtube.com/channel/ UCbV60AGIHKz2xIGvbk0LLvg (Accessed 01/03/20)

Zannettou, Savvas et al. (2018): "On the origins of memes by means of fringe web communities," Proceedings of the Internet Measurement Conference 2018, $188-202$. 